\title{
An experimental and modeling study of diethyl carbonate oxidation
}

\author{
H. Nakamura ${ }^{1,2}$, H. Curran ${ }^{1}$, A. D. Polo Córdoba ${ }^{3,4}$, W. J. Pitz ${ }^{3}$, P. Dagaut ${ }^{5}$, C. Togbé $^{5}$,

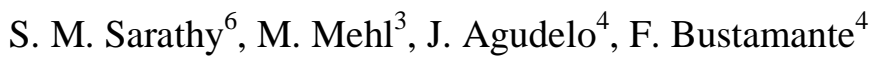

1 Combustion Chemistry Centre, National University of Ireland, Galway, Ireland

2 Institute of Fluid Science, Tohoku University, Japan

3 Lawrence Livermore National Laboratory, 7000 East Avenue, Livermore, California, USA

4 Universidad de Antioquia, calle 67 No. 53 - 108, Medellin, Colombia

5 CNRS-INSIS, 1C Avenue de la Recherche Scientifique, Orléans, France

6 Clean Combustion Research Center, King Abdullah University of Science and Technology, Thuwal, Kingdom of Saudi Arabia.

\author{
Corresponding author \\ Assistant Professor, Hisashi Nakamura \\ Institute of Fluid Science, Tohoku University, \\ 2-1-1 Katahira, Aoba-ku, Sendai 980-8577, Japan \\ TEL: +81-22-217-5296 \\ FAX: +81-22-217-5296 \\ E-mail: nakamura@edyn.ifs.tohoku.ac.jp
}




\begin{abstract}
Diethyl carbonate (DEC) is an attractive biofuel that can be used to displace petroleum-derived diesel fuel, thereby reducing $\mathrm{CO}_{2}$ and particulate emissions from diesel engines. A better understanding of DEC combustion characteristics is needed to facilitate its use in internal combustion engines. Towards this goal, ignition delay times for DEC were measured at conditions relevant to internal combustion engines using a rapid compression machine (RCM) and a shock tube. The experimental conditions investigated covered a wide range of temperatures $(660-1300 \mathrm{~K})$, a pressure of 30 bar, and equivalence ratios of $0.5,1.0$ and 2.0 in air. To provide further understanding of the intermediates formed in DEC oxidation, species concentrations were measured in a jet-stirred reactor at 10 atm over a temperature range of 500-1200 K and at equivalence ratios of $0.5,1.0$ and 2.0. These experimental measurements were used to aid the development and validation of a chemical kinetic model for DEC.

The experimental results for ignition in the RCM showed near negative temperature coefficient (NTC) behavior. Six-membered alkylperoxy radical $\left(\mathrm{RO}_{2}\right)$ isomerizations are conventionally thought to initiate low-temperature branching reactions responsible for NTC behavior, but DEC has no such possible 6- and 7-membered ring isomerizations. However, its molecular structure allows for 5-, 8- and 9-membered ring $\mathrm{RO}_{2}$ isomerizations. To provide accurate rate constants for these ring structures, $a b$ initio computations for $\mathrm{RO}_{2} \rightleftharpoons \mathrm{QOOH}$ isomerization reactions were performed. These new $\mathrm{RO}_{2}$ isomerization rate constants have been implemented in a chemical kinetic model for DEC oxidation. The model simulations have been compared with ignition delay times measured in the RCM near the NTC region. Results of the simulation were also compared with experimental results for ignition in the high-temperature region and for species concentrations in the jet-stirred reactor. Chemical kinetic insights into the oxidation of DEC were made using these experimental and modeling results.
\end{abstract}




\section{Keywords}

Ignition delay time; oxidation; shock tube; rapid compression machine; diethyl carbonate;

jet-stirred reactor 


\section{Introduction}

Diethylcarbonate (DEC) is a bio-derived fuel that can be produced from bioethanol made from sugarcane and other agricultural crops. One promising way to produce DEC is to convert ethanol using carbon monoxide and oxygen over a copper-based catalyst [1,2]. One advantage of DEC over ethanol is that it can be mixed with diesel fuel for use in compression ignition engines. Adding DEC to diesel fuel has several additional advantages including the potential for displacing petroleum-based fuel leading to a reduction in the emission of carbon dioxide $\left(\mathrm{CO}_{2}\right)$, a greenhouse gas. Moreover, when DEC is mixed with diesel fuel, the particulate emissions from a diesel engine are reduced [3]. This is particularly important when it is desirable to reduce pollutant emissions from legacy fleets of diesel vehicles that do not have modern exhaust after-treatment systems. Finally, unlike other oxygenated fuels (e.g., alcohols), DEC has a gasoline/water distribution coefficient [4] that makes it less likely for DEC to transfer to the ground water after an accidental spill.

Another application for DEC is its use as a solvent for lithium-ion batteries. Under abusive conditions, lithium-ion batteries can release solvent, which poses a flammability hazard. A chemical kinetic model for DEC is valuable to help assess the risks associated with this type of use [5].

DEC has received attention in the literature. Kozak et al. [3] tested 11 different oxygenated fuels and found that DEC, dimethyl carbonate and diethyl maleate gave the greatest reduction in particulate emissions without adversely affecting NOx emissions. Ren et al. [6] found that a DEC-diesel blend reduced the production of smoke emissions by about $35 \%$ compared to neat diesel fuel in a direct injection diesel engine.

In order to obtain a better understanding on how the addition of DEC affects diesel engine performance and emissions, engine simulations with an accurate fuel combustion chemistry 
model need to be performed. The capability of multidimensional engine simulations to use detailed chemical kinetic models has recently seen much advancement through the use of faster chemistry solvers and mechanism reduction tools [7-9]. A detailed chemical kinetic model capable of reproducing the combustion characteristics of DEC is needed to facilitate these calculations. This DEC chemical kinetic model can also be used in less computer intensive zero-dimensional (0-D) calculations to explore DEC combustion chemistry under the pressure and temperature conditions found in an engine.

In the present work, a chemical kinetic mechanism for DEC has been developed for the first time. Composition profiles from a jet-stirred reactor (JSR) and ignition delay times from a shock tube and a rapid compression machine (RCM) were obtained, as these experimental data give targets for the kinetic model over a wide range of temperatures and equivalence ratios. This rich set of experimental targets ensures that the chemical kinetic model development is appropriately tested. The following sections present a description of the experimental method, the development of the chemical kinetic model, the experimental and modeling results, and a discussion of observations.

\section{Experimental description}

\subsection{Jet-stirred reactor}

The JSR facility used has been described previously [10,11]. It consists of a small spherical fused-silica reactor (4 cm O.D.) equipped with four nozzles of $1 \mathrm{~mm}$ I.D. each. High-purity reactants were used; oxygen (99.995\% pure) and DEC (DEC anhydrous, $\geq 99 \%$ pure from Sigma-Aldrich: CAS 105-58-8, molecular structure in Fig. 1). The reactants were diluted with nitrogen $\left(<100\right.$ ppm $\left.\mathrm{H}_{2} \mathrm{O}\right)$ and quickly mixed before admission into the injectors. To minimize temperature gradients within the JSR, the reactants were preheated. A Shimadzu LC10 AD VP pump operating with an on-line degasser (Shimadzu DGU-20 A3) was used to distribute the fuel 
to an atomizer-vaporizer assembly thermally regulated at $473 \mathrm{~K}$. A high degree of dilution (1000 ppm of fuel) was used to reduce heat release and temperature gradients inside the reactor. Temperature gradients of ca. $1 \mathrm{~K} / \mathrm{cm}$ along the vertical axis of the reactor were measured by a $0.1 \mathrm{~mm}$ Pt-Pt/Rh-10\% thermocouple located inside a thin-wall silica tube to avoid catalytic effects. A movable low-pressure fused silica sonic probe was used to sample the reacting mixtures inside the reactor. The samples were transferred to analyzers via a heated line (473 K). They were analyzed online by FTIR (200 mBar; 10m path length; spectral resolution of 0.5 $\mathrm{cm}^{-1}$ ) and off-line, after collection and storage in $1 \mathrm{~L}$ Pyrex bulbs at ca. 50 mbar. Gas chromatographs (GC) equipped with capillary columns (DB-624 for oxygenates, $\mathrm{CP}-\mathrm{Al}_{2} \mathrm{O}_{3}-\mathrm{KCl}$ for hydrocarbons, and Carboplot-P7 for hydrogen and oxygen), a TCD (thermal conductivity detector), and an FID (flame ionization detector) were used for off-line analyses. The products were identified using a GC-MS (Varian V1200) operated with electron ionization $(70 \mathrm{eV})$, wherein fragmentation patterns were compared to data obtained in previous work [11] for similar species.

The experiments were performed at steady state, at a constant pressure of $10 \mathrm{~atm}$, a constant mean residence time of $0.7 \mathrm{~s}$, using $1000 \mathrm{ppm}$ of fuel and at three equivalence ratios $(\varphi=0.5,1$, and 2), which were calculated including the oxygen in the fuel. The reactants flowed constantly into the JSR and the temperature of the gases inside the reactor was increased stepwise covering a range of temperatures between 500-1200 K. A good repeatability of the measurements and a reasonably good carbon balance (lower and upper bounds of 88 and 120\%) were obtained in this series of experiments. The full experimental data is available as Supplementary Material.

The species measured included the fuel (i.e., DEC), hydrogen $\left(\mathrm{H}_{2}\right)$, oxygen $\left(\mathrm{O}_{2}\right)$, water $\left(\mathrm{H}_{2} \mathrm{O}\right)$, carbon monoxide $(\mathrm{CO})$, carbon dioxide $\left(\mathrm{CO}_{2}\right)$, methane $\left(\mathrm{CH}_{4}\right)$, ethanol $\left(\mathrm{C}_{2} \mathrm{H}_{5} \mathrm{OH}\right)$, ethane $\left(\mathrm{C}_{2} \mathrm{H}_{6}\right)$, acetylene $\left(\mathrm{C}_{2} \mathrm{H}_{2}\right)$, ethylene $\left(\mathrm{C}_{2} \mathrm{H}_{4}\right)$, ethylene oxide $\left(\mathrm{C}_{2} \mathrm{H}_{4} \mathrm{O}-12\right)$, ethane $\left(\mathrm{C}_{2} \mathrm{H}_{6}\right)$, propene 
$\left(\mathrm{C}_{3} \mathrm{H}_{6}\right)$, propane $\left(\mathrm{C}_{3} \mathrm{H}_{8}\right)$, acetaldehyde $\left(\mathrm{CH}_{3} \mathrm{CHO}\right)$, and formaldehyde $\left(\mathrm{CH}_{2} \mathrm{O}\right)$. The uncertainty in these concentrations is ca. $\pm 15 \%$, in reactor temperature is $\pm 5 \mathrm{~K}$ and in reactor residence time is $\pm 0.02 \mathrm{~s}$.

\subsection{Shock tube}

Ignition delay times were measured at high-temperature using a high-pressure shock tube, details of which can be found in previous publications $[12,13]$. Briefly, the shock tube is $8.7 \mathrm{~m}$ long and $63.5 \mathrm{~mm}$ in the internal diameter. A double-diaphragm section divides the tube into a 3 $\mathrm{m}$ long driver section and a $5.7 \mathrm{~m}$ driven section. Aluminum plates of $1.5 \mathrm{~mm}$ thickness were used as the diaphragm material. A helium (99.99\% pure; BOC Ireland) and nitrogen (99.99\% pure; BOC Ireland) mixture were used as the driver gas, where the mixing ratio was varied from 90:10 to 100:0 (He: $\left.\mathrm{N}_{2}\right)$ to obtain the reflected shock pressure of 30 atm and the desired test duration. Six pressure transducers on the sidewall (PCB; 113A24) and one at the endwall (Kistler; 603B) were used to measure the velocity of the incident shock wave, which was used to calculate the temperature of the mixtures behind the reflected shock wave using the program Gaseq [14]. Pressures behind the reflected shock wave were measured using the pressure transducer in the endwall. The pressure rise before ignition is approximately $3 \% / \mathrm{ms}$ in the present shock tube. The experiments were conducted for DEC/air mixtures of equivalence ratios of $0.5,1.0$ and 2.0. DEC was obtained from Tokyo Chemical Ltd at over 98.0\% purity (GC grade). Oxygen (99.5\%) and nitrogen (99.99\%) supplied by BOC Ireland were used to make air $\left(\mathrm{O}_{2}: \mathrm{N}_{2}=21: 79\right)$. The initial temperature of the DEC/air mixture was $373 \mathrm{~K}$ for equivalence ratio of 0.5 and $383 \mathrm{~K}$ for equivalence ratios of 1.0 and 2.0. The reflected shock temperature ranged from approximately $940 \mathrm{~K}$ to $1240 \mathrm{~K}$. The initial pressure of the DEC/air mixture was varied from 0.47 to $1.05 \mathrm{~atm}$ to obtain a reflected shock pressure of $30 \mathrm{~atm}$. Estimated uncertainty limits of the measurements are $\pm 1 \%$ in reflected shock temperature, $\pm 5 \%$ in reflected shock pressure, $\pm 2 \%$ in mixture concentration and $\pm 15 \%$ in ignition delay time. All experimental data 
are available as Supplementary Material.

\subsection{Rapid compression machine}

Ignition delay times at low-temperature were measured using an opposed-piston rapid compression machine originally developed by Affleck and Thomas at Shell-Thornton [15]. Creviced piston heads, with an inner diameter of $38.2 \mathrm{~mm}$, were used in order to improve the post-compression temperature homogeneity in the combustion chamber [16]. The compression ratio was approximately $15: 1$ in this study. In order to attain the desired pressure and temperature at the end of compression, the initial pressures and temperatures and inert gas compositions $\left(\mathrm{N}_{2}\right.$ or Ar) were varied. A pressure transducer (Kistler; 603B) was installed in the combustion chamber. The pressure transducer was coated with silicone to reduce its temperature sensitivity. Pressure traces were recorded using a digital oscilloscope. The compressed gas temperature was calculated using Gaseq [14]. Non-reactive experiments were performed in which oxygen was replaced by nitrogen in a mixture, in order to obtain pressure-time histories which are converted to volume-time histories which were used in chemical kinetic simulations to simulate the effects of compression and heat loss. Details of the facility and experimental procedures are given in $[17,18]$. The same heating system as used in previous studies for alkylbenzenes [12,13], whose vapor pressures are much lower than that of DEC, was used in this study. The initial temperature was varied from 333 to $413 \mathrm{~K}$ depending on the desired compressed-gas temperature. The compressed-gas temperature in the RCM experiments ranged from approximately $690-960 \mathrm{~K}$. The initial pressure was varied from 0.82 to 0.99 atm to obtain a compressed gas pressure of $30 \mathrm{~atm}$. The experiments were conducted for DEC/'air' mixtures of equivalence ratios of $0.5,1.0$ and 2.0. The oxygen in the fuel was taken considered when determining the equivalence ratio. DEC was obtained from Tokyo Chemical Ltd at over 98.0\% purity (GC grade). Oxygen (99.5\%), nitrogen (99.99\%) and argon (99.99\%) supplied by BOC Ireland were used to make 'air' $\left(\mathrm{O}_{2}\right.$ :inert $\left.=21: 79\right)$. Estimated uncertainty limits of the 
measurements are $\pm 5 \mathrm{~K}$ in compressed gas temperature, $\pm 5 \%$ in compressed gas pressure, $\pm 2 \%$ in mixture concentration and $\pm 10 \%$ in ignition delay time. All non-reactive pressure traces and experimental data are available as Supplementary Material.

\section{Chemical kinetic modeling}

The detailed chemical kinetic reaction mechanism was developed based on our mechanism for dimethylcarbonate [19]. For the $\mathrm{C}_{1}$ to $\mathrm{C}_{4}$ chemistry, AramcoMech 1.3 [20] was used. The molecular structure of DEC is shown in Fig. 1. The key reactions for DEC are shown in Table 1 and discussed below.

\subsection{DEC molecular elimination}

The unimolecular decomposition of DEC via molecular elimination (i.e., retroene reaction) is amongst the most important due to its low activation energy. Molecular elimination of the fuel ( $\mathrm{R} 1$ in Table 1) produces ethylene and ethyl formic acid (EFA), and is assigned a rate constant taken from the shock tube measurements of Herzler et al. [21]. Bennadji et al. [22] and Metcalfe et al. [23] reported that ethyl butanoate largely decomposes into butanoic acid and ethylene; similarly the present analysis shows that DEC mainly decomposes into ethoxyformic acid and ethylene as it proceeds through a 6-membered ring transition state involving an ethyl ester group. However, one difference is that in DEC the molecular elimination reaction can occur with either of its two ethyl ester groups, while ethyl butanoate only has one ester group available. The rate constant from Herzler for DEC (Table 1) is about 7 times faster at $800 \mathrm{~K}$ than that of Bennadji [22] and Metcalfe [23]. Although both paths lead to ethylene, EFA is formed in the case of DEC, while butanoic acid is formed from ethyl butanoate. Subsequently, EFA undergoes rapid molecular elimination forming ethanol and $\mathrm{CO}_{2}(\mathrm{R} 2)$ [21]. The activation energy for $\mathrm{R} 2$ was taken from the barrier height computed by Notario et al. [24] and the pre-exponential factor was derived from their computed rate constant at $600 \mathrm{~K}$. These two reactions ( $\mathrm{R} 1$ and $\mathrm{R} 2)$ lead to the 
net reaction of DEC to form ethylene, ethanol and $\mathrm{CO}_{2}$ which is the main consumption path of DEC under all conditions investigated in this study.

\subsection{H-atom abstraction reactions}

Rate constants for $\mathrm{H}$-atom abstraction reactions from DEC were determined by analogy with $\mathrm{H}$-atom abstractions from ethyl esters. These rate constants were taken from theoretical calculations by Mendes et al. for ethyl esters with $\dot{\mathrm{OH}}$ [25] and $\mathrm{HO}_{2}$ radicals [26]. However, preliminary kinetic modeling simulations showed that the calculated rate constants were too slow in predicting experimental ignition delay times, so that these rates were increased by a factor of 2.5, which is the estimated uncertainty limit stated by Mendes et al. [25,26]. For

$\mathrm{H}$-atom abstraction reactions from the fuel by other small radicals (e.g., $\dot{\mathrm{H}}, \mathrm{O}$ and $\dot{\mathrm{C}} \mathrm{H}_{3}$ ), the rate constants were based on analogy with alkanes [27] with some modifications noted below. DEC has two $\mathrm{CH}_{2}$ groups at the $\alpha$ site (Fig. 1) (i.e. secondary groups) whose $\mathrm{C}-\mathrm{H}$ bonds are weaker than those in a $\mathrm{CH}_{2}$ group in an alkane because the carbon is also linked to an oxygen atom. Therefore, we have used the rate constant for a weaker tertiary $\mathrm{C}-\mathrm{H}$ bond [27] in an alkane for abstraction from this site, multiplying by 2 for the degeneracy of the two $\mathrm{H}$ atoms available for abstraction. Further studies (experimental and/or computational) are needed, since it is likely that, in the transition state formed during abstraction by oxygenated radicals such as $\dot{\mathrm{O}} \mathrm{H}$ and $\mathrm{HO}_{2}$, hydrogen bonding would occur between the $\mathrm{H}$-atom on the abstracting radical and the oxygen atom in DEC as observed in ethers [28] and alcohols [29]. For the methyl group in DEC (the $\beta$ site), the rate constant is assumed to be the same as a methyl group in an alkane [27].

\subsection{Radical decomposition}

For this reaction type, the rate constant is often specified in the reverse, exothermic direction [27] and the decomposition rate is computed from the thermodynamic properties. This is the case for reaction $\mathrm{R} 3$ which is the reverse of the decomposition of the $\beta$-DEC radical 
(CJCOC*OOCC) and consists of the addition of a carbon-centered, resonantly-stabilized radical $(\mathrm{CCOC} * \mathrm{OOJ})$ to ethylene. Little is known about the rate constant for this reaction which requires the breaking of the resonance of the radical with an accompanying activation energy. Also, much less is known about the reaction of oxygen-centered radicals compared to carbon-centered ones. We treated this reaction with the same rate as a $\mathrm{C}_{2} \mathrm{H}_{5} \mathrm{O}$ radical adding to ethylene [30]. Further investigation is needed into this important reaction type which also controls the decomposition of ester radicals. For reaction R4, the reverse reaction is the decomposition of the $\alpha$-DEC radical. The forward reaction involves a carbon-centered radical adding to the oxygen side of double bond on acetaldehyde. Addition to $\mathrm{C}=\mathrm{O}$ double bonds is less well understood than to $\mathrm{C}=\mathrm{C}$ double bonds. We chose the rate constant from an analogous reaction involving formaldehyde [31].

Ethoxy formyl radicals are formed from R4 and rate constants for their decomposition reactions (R5 and R6) are taken from the analogous reaction of the methoxy-formyl radical decomposition reactions. The methoxy-formyl radical decomposition rate constants are pressure dependent and have been recently computed by Klippenstein [32]. In general, these alkyoxy-formyl reactions lead to products containing either $\mathrm{CO}$ or $\mathrm{CO}_{2}$. The branching ratio using the new rate constants from Klippenstein differ from the branching ratio using the previous rate constants for methoxy-formyl radical decomposition. The new branching ratio to the $\mathrm{CO}$ product channel is negligible whereas the old branching ratio to $\mathrm{CO}$ was $\sim 30 \%$ at $1200 \mathrm{~K}$ [19]. This change in branching ratio has important implications for the soot formation rates of oxygenated fuels in the case of esters and di-alkyl carbonates. If $\mathrm{CO}$ is formed, the oxygen atom in the fuel sequesters one carbon atom in the fuel, $\mathrm{CO}$ is produced, and the formation of soot precursors from the sequestered carbon atom is avoided. If $\mathrm{CO}_{2}$ is formed, one of the two oxygen atoms in the fuel is "wasted" because it does not sequester a carbon atom and thereby prevent it from contributing to soot precursor species [33]. If this new branching ratio is correct, the use of 
esters and di-carbonates to reduce soot in diesel engines would be less effective from a chemical kinetic point of view, than previously thought. Also, the new branching ratio will help reduce the discrepancies between model simulations and experimental shock tube measurements of $\mathrm{CO}_{2}$ yields in the shock tube experiments of esters where the model predictions for $\mathrm{CO}_{2}$ yields were lower than experimental yields [34]. These discrepancies were largely attributed to the branching ratio of the methoxy-formyl radical decomposition reaction by Farooq et al. [34].

\subsection{Ethanol reactions}

Because DEC undergoes a sequence of molecular elimination reactions that form ethanol, its combustion has an important role in DEC oxidation. H-atom abstraction reactions from ethanol by $\dot{\mathrm{OH}}$ and $\mathrm{HO}_{2}$ radicals showed high sensitivity coefficients in the JSR case as discussed later. The base chemistry [20] of the present chemistry includes ethanol reactions. However, we have included recently updated rate constants of $\mathrm{H}$-atom abstraction reactions from ethanol based on the work of Mittal et al. [35].

In the base chemistry, rate constants of ethanol $\mathrm{H}$-atom abstraction reactions with $\dot{\mathrm{OH}}$ and $\mathrm{HO}_{2}$ radicals are taken from the recent work of Mittal et al. [35]. The total rate constant for abstraction by $\dot{\mathrm{OH}}$ radicals is based on the study of Sivaramakrishnan et al. [36] but their branching ratio for abstraction from each of the three sites on the ethanol molecule was modified to improve agreement for ethylene concentration profiles in JSR and flow-reactor studies as discussed in the work of Mittal et al. [35]. The branching ratios of the rate constants for H-atom abstraction by $\dot{\mathrm{OH}}$ radicals are particularly important as abstraction at the site alpha to the functional group leads to the formation of a $\mathrm{CH}_{3} \dot{\mathrm{C}} \mathrm{HOH}$ radical which subsequently forms acetaldehyde and a hydrogen atom, while abstraction of a $\mathrm{H}$-atom beta to the functional group generates the $\dot{\mathrm{C}} \mathrm{H}_{2} \mathrm{CH}_{2} \mathrm{OH}$ radical which decomposes to ethylene and an hydroxyl radical. Our total rate constant for abstraction by $\mathrm{OH}$ radical is within $15 \%$ at $900 \mathrm{~K}$ and $10 \%$ at $1300 \mathrm{~K}$ of 
that recently measured by Stranic et al. [37], while our recommended branching ratio of the $\beta$-site is approximately $30 \%$ in the temperature range 300-1650 K, while Stranic et al. measured a branching ratio of between $20-25 \%$. Abstraction by $\mathrm{HO}_{2}$ radicals are based on the work of Zhou et al. [38].

\section{5 $\mathrm{R} \dot{\mathrm{O}}_{2} \rightleftharpoons \mathrm{QOOH}$ isomerization and related reactions}

Due to its structure, DEC does not allow formation of 6- and 7-membered ring structures for $\mathrm{RO}_{2} \rightleftharpoons \mathrm{QOOH}$ isomerization, which are important to the low-temperature oxidation of alkanes. This indicates that DEC may not show significant low-temperature oxidation. However, as discussed later, the present RCM experiment showed near negative temperature coefficient (NTC) behavior. Rate constants of $\mathrm{RO}_{2} \rightleftharpoons \mathrm{QOOH}$ isomerization reactions for carbonate esters are not well understood. Therefore, rate constants of $\mathrm{RO}_{2} \rightleftharpoons \mathrm{QOOH}$ isomerization reactions for DEC were calculated using ab initio methods and the rate constants obtained were compared with rate rules for alkane $\mathrm{RO}_{2} \rightleftharpoons \mathrm{QOOH}$ isomerizations to determine the relevance of alkane rate rules for DEC oxidation.

Gaussian 09 (Revision C.01) [39] was used to perform all structural optimization and energy calculations. The MP2/6-311G(d,p) method and basis set was used for geometry optimizations, frequency calculations and hindered-rotor scans. Intrinsic reaction coordinate (IRC) calculations were performed in order to confirm the connection between structures of transition state and local minima. The CBS-QB3, CCSD(T)/cc-pVTZ and G4 methods were used for single point energy calculations. The rate constant for high-pressure limit was calculated using THERM in the MultiWell suite (Version 2011.3) [40,41].

Isomerization reactions of secondary $\alpha-\mathrm{RO}_{2}$ (see Fig. 1 for $\alpha$ location on DEC) were considered first because $\alpha-\mathrm{RO} \dot{\mathrm{O}}_{2}$ radicals are produced in higher concentrations than $\beta-\mathrm{RO} \dot{\mathrm{O}}_{2}$ ones due to the 
easy abstraction of the weakly-bonded $\mathrm{H}$ atom on the $\alpha$ site in DEC. Also, $\alpha-\mathrm{RO}_{2}$ radicals can form smaller 8- and 9-membered ring transition states across the central carbonate structure which allows a higher A-factors overall than for the $\beta-\dot{\mathrm{O}}_{2}$ radicals which can only form larger 9- and 10-membered ring structures. The 9- and 10-membered ring structures contained more rotors that are "tied up" in the $\mathrm{RO}_{2}$ radical isomerization transition state (TST) compared to the 8-membered ring. These addition rotors lead to an accompanying loss of entropy in the TST.

Figure 2 shows potential energy surface of the $\alpha-\mathrm{RO}_{2} \rightleftharpoons \mathrm{QOOH}$ isomerization reactions. Relative energies to the global minimum energy of $\alpha-\dot{R O}_{2}$ radicals obtained by CBS-QB3, CCSD(T)/cc-pVTZ and G4 are shown in normal, italic and bold fonts, respectively. The energy barrier of the 8-membered ring structure is very close to that of the 9-membered ring structure, and that of the 5-membered ring structure is $\sim 10 \mathrm{kcal}$ higher than those of the 8 - and 9-membered ring structures. For all structures except the transition states, the relative energies obtained by the three methods are in good agreement, being within $\pm 0.3 \mathrm{kcal} / \mathrm{mol}$ of one another. On the other hand, for the transition state structures, the relative energies obtained by CBS-QB3 method are 1-2 kcal/mol lower than those obtained by CCSD(T)/cc-pVTZ and G4 methods.

Figure 3 shows computed rate constants of the $\alpha-\mathrm{RO}_{2} \rightleftharpoons \mathrm{QOOH}$ isomerization reactions. Solid lines, dashed lines and lines with symbols indicate 5-, 8- and 9-membered ring structures, respectively. Black, red and blue lines indicate CBS-QB3, CCSD(T)/cc-pVTZ and G4, respectively. A rate rule of alkane $\mathrm{RO}_{2} \rightleftharpoons \mathrm{QOOH}$ isomerization derived from $a b$ initio calculations by Villano et al. [42] is also shown by a turquoise line to compare it with the computed rate constants. For all of the methods in the low-temperature region, the 8-membered ring structure shows the highest rate constant while the 5-membered ring structure is the lowest. For all of the structures, the rate constants obtained by the CCSD(T)/cc-pVTZ method are in good agreement with those generated by G4, being within a factor of 2 of one another through 
the complete temperature range. The rate constants obtained by CBS-QB3 are 2 to 5 times higher than those calculated by $\operatorname{CCSD}(\mathrm{T}) / \mathrm{cc}-\mathrm{pVTZ}$ and G4 in the low-temperature region, and are within a factor of 2 of the alkane rate rules. Note that the alkane rate rules [42] were developed based on CBS-QB3 calculations.

CBS-QB3 calculations have been successfully applied in numerous kinetic studies for alkanes [43-45] although rate constants obtained by CBS-QB3 were significantly different from those obtained by $\operatorname{CCSD}(\mathrm{T}) / \mathrm{cc}-\mathrm{pVTZ}$ and G4 in this study. Further investigation is necessary to examine why this is so. Some issues with CBS-QB3 when computing the rate constants for formation of cyclic ethers have been reported by Wijaya et al. [46]. They found similar discrepancies in the computed energy barriers between CBS-QB3 and other methods when computing TS energies for an oxygenate as a reactant. They attributed the erroneous barrier for CBS-QB3 to the population localization method employed. $\Delta \mathrm{E}($ Empirical $)$ was small $(<0.07$ kcal) in our case, which shows that the uncertainty introduced by the population localization method was also limited. Since ignition delay times computed with the rate constants obtained by $\operatorname{CCSD}(\mathrm{T}) / \mathrm{cc}-\mathrm{pVTZ}$ and G4 were 3 to 10 times longer than experimental ones in the low-temperature region, we have decided to use the rate constants obtained by CBS-QB3 for the parent DEC radicals which give better agreement with the experimental measurements. The employed rate constants of $\alpha-\mathrm{RO}_{2} \rightleftharpoons \mathrm{QOOH}$ isomerization reactions are shown in R7-9 of Table 1. The same computations with CBS-QB3 were also conducted for $\beta-\mathrm{RO}_{2} \rightleftharpoons \mathrm{QOOH}$ isomerization reactions and their rate constants are shown as well in R10-11 in Table 1.

\subsection{Thermochemical and transport data}

The thermodynamic parameters for the species are very important because they are used to determine reverse rate constants and determine the temporal evolution of the heat release rate during the ignition process. The THERM [47] software was used to compute the 
thermochemical properties of DEC-related species. The THERM group values and bond dissociation energies are from Benson [48], Bozzelli [49] and Glaude et al. [19].

The transport properties of stable species were determined from the correlations developed by Tee et al. [50] to calculate the LJ collision diameter and potential well depth using the critical pressure, critical temperature, and acentric factor. For DEC, these properties were taken from Yaws [51]. For species that had no critical pressure and critical temperature available, the transport properties of species of similar size and structure were used. For radical species, the transport properties of the parent species were used. The transport data were not used in this study, but are being made available for flame simulations if and when required.

Short timescales in the chemical kinetic mechanism and discontinuities in the thermodynamic states can cause chemical kinetics solvers to fail. The detailed chemical kinetic mechanism and thermodynamics parameter file were analyzed by LLNL mechanism tools to identify forward and reverse rate constants that are out-of-range (e.g. bimolecular reaction rates that greatly exceed molecular collision rates, either in the forward or reverse direction, and unimolecular decomposition rates with timescales below $10^{-15} \mathrm{~s}$ ) [52]. These out-of-range rate constants are usually typographical or estimation errors, and they were identified and fixed. Also, the LLNL tools were used to examine thermodynamic parameters for discontinuities at the transition temperature from the low to high temperature fit. Some discontinuities were found and repaired. The detailed chemical mechanism, thermodynamic parameters, transport parameters, and species glossary are available as supplementary data. The total number of species is 355 and that of reactions is 1959 .

\section{Results}

\subsection{Composition profiles}

The CHEMKIN-PRO (version 15113) [53] transient perfectly-stirred reactor code was used to 
compute steady-state species concentrations for comparison to the jet stirred reactor data for DEC. The transient calculations were carried out for a $20 \mathrm{~s}$ calculation time for each reactor temperature considered to ensure steady-state conditions were achieved.

A comparison of the experimental and computed species profiles as a function of reactor temperature is shown in Fig. 4. Each column in the figure corresponds to a specific equivalence ratio (e.g., $0.5,1.0$, or 2.0), while each row is a separate suite of species. As seen in the first row of plots, the fuel profile is very well simulated by the chemical kinetic model at all equivalence ratios. For the present experimental conditions, the JSR experiment does not show NTC behavior which would be seen as a "shoulder" in the fuel profile. The fuel is mainly consumed by molecular elimination to ethylene and ethyl-hydrogen-carbonate (R1). The latter species also undergoes a rapid molecular elimination reaction (R2) to ethanol and carbon dioxide. This sequence leads to the large ethanol and ethylene peaks in Fig. 4. The model prediction is low by $\sim 50 \%$ for ethanol (first row) and about $\sim 40 \%$ low for ethylene (third row). This result suggests that there are other species in the model that are being over-produced to compensate for the under-production of ethanol and ethylene. However, an examination of the results in Fig. 4 fails to show species over-produced by the model. These discrepancies between the model and experiment may be due to a $15 \%$ excess of carbon in the experimental results at the peak location. The maximum concentrations of formaldehyde and acetaldehyde occur earlier in the simulations than in the experiments (i.e, their profiles are shifted towards lower temperatures). These species are formed upon ethanol decomposition, so it suggests that ethanol may be consumed too rapidly in the simulations when compared to the experiments. However, the chemistry of ethanol $[20,35]$ and ethylene $[54,55]$ has recently been widely validated over a wide range of pressures, temperatures and fuel/oxygen/diluent ratio and so we believe that, if there is a deficiency in the mechanism, it is more likely due to reactions associated with the primary fuel mechanism than with either the ethanol or ethylene sub-mechanisms. The hydrogen 
mole fractions are fairly well predicted by the model for the fuel-lean case with under-prediction at high temperature for the stoichiometric and fuel-rich case.

In the second row, the oxygen, water and carbon dioxide profiles are overall well-predicted by the model, with some overestimate by the model of oxygen at high temperature for the fuel-lean case. $\mathrm{CO}$ is very well predicted and is often used as an overall predictor of fuel reactivity [56].

In the third row, the predicted formaldehyde maximum is close to the experimental one, but it peaks earlier than the experiments by about $30 \mathrm{~K}$. Methane is also well-predicted by the model. In the fourth row, the predicted acetaldehyde profile provides an excellent match to the experiments, with a slight shift to lower temperatures of about $20 \mathrm{~K}$. About $90 \mathrm{ppm}$ formic acid was predicted by the model at $\varphi=1.0$, but an experimental value could not be obtained because the formic acid signal overlaps with ethyl hydrogen carbonate in the FTIR and formic acid is not detectable with the GC using FID.

Figure 5 presents a reaction flux analysis for DEC oxidation in the JSR when the fuel is $50 \%$ consumed $(780 \mathrm{~K}, 10 \mathrm{~atm}, \varphi=1.0)$. At these conditions, $96 \%$ of the fuel is consumed by two sequential molecular elimination reactions forming ethylene, ethanol and $\mathrm{CO}_{2}$. There are three other products of DEC in the JSR at the present conditions. $\beta$-Fuel radicals are formed from $\mathrm{H}$-atom abstraction reactions by $\dot{\mathrm{O}} \mathrm{H}$ radicals and the consumption of $\beta$-fuel radicals to $\beta$ - $\mathrm{RO}_{2}$ radicals is balanced with the formation of $\beta$-fuel radicals from $\beta$ - $\dot{\mathrm{O}}_{2}$ radicals. $\alpha$-Fuel radicals are formed from $\mathrm{H}$-atom abstraction reactions with $\dot{\mathrm{O}} \mathrm{H}, \dot{\mathrm{H}}$ and $\mathrm{HO}_{2}$ radicals and the consumption of $\alpha$-fuel radicals to $\alpha-\mathrm{RO}_{2}$ radicals is almost balanced with the formation of $\alpha$-fuel radicals from $\alpha-\mathrm{RO}_{2}$ radicals. The net isomerization rate of $\alpha-\mathrm{RO}_{2}$ to $\alpha-\mathrm{ROOH}$ is negligible. There is a small flux from $\alpha$-fuel radicals to form acetaldehyde and ethoxy formyl radical. Ethoxy formyl radicals decompose to ethyl radicals and $\mathrm{CO}_{2}$. 
A sensitivity analysis was performed at the same conditions as those presented in Fig. 5 to provide further insight into DEC oxidation. Figure 6 presents the sensitivity, using CHEMKIN-PRO [53], of the $\dot{\mathrm{OH}}$ concentration to changes in the rate constants at $780 \mathrm{~K}, 10 \mathrm{~atm}$ and at $\varphi=0.5,1.0$ and 2.0. The sensitivity with respect to $\dot{\mathrm{O} H}$ was investigated because the $\dot{\mathrm{O} H}$ radical is the most important one reacting with the fuel and consuming intermediate products under the present JSR conditions. The analysis provides insight into the reactions that are controlling the formation and consumption of $\dot{\mathrm{OH}}$ radicals. As seen in Fig. 6, the formation of $\dot{\mathrm{O}} \mathrm{H}$ radicals is controlled by the reaction sequence of the fuel reacting with $\mathrm{HO}_{2}$ to form $\mathrm{H}_{2} \mathrm{O}_{2}$, followed by $\mathrm{H}_{2} \mathrm{O}_{2}$ decomposition. This is a chain branching path because two $\dot{\mathrm{O}} \mathrm{H}$ radicals are formed for each $\mathrm{HO}_{2}$ radical that is consumed. This branching path has been reported as being important in many studies (e.g. Pitz et al. [32]) of fuel oxidation at low- to intermediate-temperatures and elevated pressures. It is interesting to note that $\mathrm{HO}_{2}$ radicals preferentially abstract $\alpha \mathrm{H}$-atoms as these have weaker $\mathrm{C}-\mathrm{H}$ bonds compared to the $\beta$ site. The main reaction that inhibits $\dot{\mathrm{O}} \mathrm{H}$ radical formation is the self-reaction of $\mathrm{HO}_{2}$ radicals to form $\mathrm{H}_{2} \mathrm{O}_{2}$, as this is a chain termination path.

\subsection{Ignition delay times}

The CHEMKIN-PRO (version 15113) [53] transient closed homogeneous batch reactor was used for the simulation of ignition delay times and the present kinetic model was validated against ignition data obtained in both the shock tube and in the RCM experiments. For the simulation of the RCM experiments, variable volume-time histories were employed in the Chemkin simulation to include facility effects including reaction during compression and heat loss. These variable volume-time histories were generated from non-reactive pressure traces. All non-reactive pressure traces are available as Supplementary Material. Constant volume conditions were employed in the shock tube simulations, without including any facility effect. This assumption is made possible by the relative shortness of the ignition delay times measured 
in this shock tube study (less than $2 \mathrm{~ms}$ in most cases) wherein the pressure rise before ignition $(3 \% / \mathrm{ms})$ does not significantly affect the simulation of such short ignition delay times.

Figure 7 shows experimental and model predicted ignition delay times for DEC at equivalence ratios of $0.5,1.0$ and 2.0 and an initial pressure of 30 atm. From the experimental results, ignition delay times exponentially increase with an increase in inverse temperature over the entire temperature region at $\varphi=0.5$ and the high-temperature region at $\varphi=1.0$ and 2.0. On the other hand, in the low-temperature region at $\varphi=1.0$ and 2.0, the slopes of the curves decrease compared to the $\varphi=0.5$ case. The curve for $\varphi=2$ exhibits near NTC behavior. The present mechanism captures the overall tendency of the experimental results. However, the model over-predicts ignition delays in the low-temperature region by up to a factor of two for $\varphi=2$. Note that two-stage ignition was not observed in the near NTC region in experiments.

A reaction flux analysis was carried out at $800 \mathrm{~K}, 30 \mathrm{~atm}$ and $15 \%$ fuel conversion for a series of equivalence ratios $(0.5,1.0$ and 2.0$)$ in order to investigate the important reactions controlling DEC ignition, as shown in Fig. 8. The major paths for DEC consumption are decomposition to molecular products and $\mathrm{H}$-atom abstraction reactions to form $\alpha$ - and $\beta$-fuel radicals. $\mathrm{C}_{2} \mathrm{H}_{4}$ and $\mathrm{CCOC} * \mathrm{OOH}$ are formed in the molecular elimination reaction and its flux decreases with an increase in equivalence ratio. $\mathrm{CCOC} * \mathrm{OOH}$ further decomposes to $\mathrm{CO}_{2}$ and ethanol. For the $\mathrm{H}$-atom abstraction reactions, $\alpha$-fuel radicals (CCJOC*OOCC) are mainly formed. The reaction of the $\alpha$-fuel radicals with $\mathrm{O}_{2}$ is in partial equilibrium with its reverse reaction. A small amount of $\alpha$-fuel radicals decompose to form the ethyl formyl radical $\left(\mathrm{CCOCJ}^{*} \mathrm{O}\right)$ and acetaldehyde at $\varphi=2$. $\mathrm{CCOCJ} * \mathrm{O}$ further decomposes to $\dot{\mathrm{C}}_{2} \mathrm{H}_{5}$ and $\mathrm{CO}_{2}$. (The alternative decomposition path for ethyl formyl radical is to $\mathrm{C}_{2} \mathrm{H}_{5} \mathrm{O}$ and $\mathrm{CO}$, but is not significant.)

For $\beta$-Fuel radicals, they are consumed to form $\beta-\mathrm{RO}{ }_{2}$ radicals. There are two small fluxes for the consumption of $\beta-\mathrm{RO}_{2}$. One of these leads to a $\mathrm{QOOH}$ type species. The results of the 
reaction-path analyses shows that chain-propagation reactions like $\mathrm{QOOH} \rightarrow$ Products+ÖH and $\dot{\mathrm{O}}_{2} \mathrm{QOOH} \rightarrow$ Products $+\dot{\mathrm{OH}}$ and chain-branching reactions like $\mathrm{ROOH} \rightarrow \mathrm{RO}+\dot{\mathrm{O}} \mathrm{H}$ are not significant in the low-temperature oxidation of DEC compared to that of alkanes.

A brute force sensitivity analysis including all rate constants was performed at $800 \mathrm{~K}$ and $30 \mathrm{~atm}$ for a series of equivalence ratio $(0.5,1.0$ and 2.0$)$, assuming constant volume combustion. The analyses were performed by increasing and decreasing both the forward and reverse rate constants by a factor of two in turn, with a sensitivity coefficient expressed using the formula:

$$
S=\frac{\ln \left(\tau_{+} / \tau_{-}\right)}{\ln \left(k_{+} / k_{-}\right)}=\frac{\ln \left(\tau_{+} / \tau_{-}\right)}{\ln (2 / 0.5)}
$$

A positive sensitivity coefficient indicates an inhibiting reaction, while a negative sensitivity coefficient indicates a reaction promoting reactivity. The sensitivity results were confirmed using a recently developed LLNL sensitivity analysis tool [52]. The LLNL sensitivity tool perturbed 3361 reactions (this includes a separate perturbation of the forward and reverse rate). For each the three equivalence ratios, the code completed its calculations in one minute using 48 CPU cores. The same calculations with a commercially-available solver on one CPU core took 3 days.

Reactions with sensitivity coefficients higher than 0.1 and lower than -0.1 and related reactions are shown in Fig. 9. The reactions are labeled to aid in the discussion of the results. The $\mathrm{HO}_{2}$ elimination reactions of $\alpha$ - and $\beta-\mathrm{RO}_{2}$ radicals (A1, A2) inhibit reactivity. The elimination reaction of the $\alpha-\mathrm{RO} \dot{\mathrm{O}}_{2}$ radical shows a higher sensitivity coefficient than that of the $\beta-\mathrm{RO} \dot{\mathrm{O}}_{2}$ radical. The reactions $\mathrm{A} 3$ and $\mathrm{A} 4$ are $\beta-\mathrm{RO}_{2} \rightleftharpoons \mathrm{QOOH}$ isomerization reactions. Reaction $\mathrm{A} 3$ promotes reactivity because it eventually leads to a ketohydroperoxide $+\dot{\mathrm{OH}}$, while reaction A4 inhibits reactivity because its product decomposes to form relatively unreactive $\mathrm{HO}_{2}$ radicals. The decomposition reaction of $\alpha$-DEC (A5) inhibits reactivity. The sensitivity coefficients of 
reaction A5 at $\varphi=1.0$ and 2.0 are higher than that at $\varphi=0.5$. A6 is the reaction of the $\alpha$-radical with $\mathrm{HO}_{2}$ and shows a high sensitivity coefficient. Reactions A7-A12 are H-atom abstraction reactions of DEC. Among these reactions, the $\mathrm{H}$-atom abstraction by $\dot{\mathrm{O}} \mathrm{H}$ and $\mathrm{HO}_{2}$ radicals from fuel radicals (A9-12) show very high sensitivity coefficients at all equivalence ratios. Reactions A13-15 are part of ethanol oxidation reactions and show high sensitivity. Reactions A16 and A17 are important chain-branching and termination reactions involving $\mathrm{HO}_{2}$ radicals which promote and inhibit reactivity, respectively. The sensitivity coefficients of $\mathrm{RO}_{2} \rightleftharpoons \mathrm{QOOH}$ isomerization reactions are not so high compared with those of $\mathrm{H}$-atom abstraction reactions from DEC. However, more accurate rate constants of $\mathrm{RO}_{2} \rightleftharpoons \mathrm{QOOH}$ isomerization reactions need to be estimated in the future because the present $a b$ initio computations showed large uncertainties for rate constants of $\mathrm{RO}_{2} \rightleftharpoons \mathrm{QOOH}$ isomerization reactions depending on the method used. Also recall that the rate constants calculated using CBS-QB3 method were 2-5 times faster in low temperature region than those calculated using $\operatorname{CCSD}(\mathrm{T}) / \mathrm{cc}-\mathrm{pVTZ}$ or G4 (Fig. 3).

\section{Discussion}

As discussed in the introduction, prior engine combustion studies $[3,4]$ have shown that the addition of DEC to diesel fuel can significantly reduce particulate matter emissions. Westbrook et al. [59] performed chemical kinetic modeling simulations of a wide range of oxygenates to elucidate the effects of fuel structure on soot emission in diesel engines. They explain that the concentration of soot precursors (e.g., ethylene, acetylene, propene, etc.) formed during premixed auto-ignition is a good indicator of the sooting propensity of real diesel fuels in the premixed combustion region of a reacting spray. Their results suggest that, for a fixed oxygen mass fraction, fuels with alcohol functionalities are less likely to form soot precursors than fuels with ester functionalities (e.g., methyl butanoate and dimethyl carbonate). Furthermore, the ester 
moiety is shown to be an inefficient use of fuel-bound oxygen because, upon combustion, the formation of $\mathrm{CO}_{2}$ is favored over $\mathrm{CO}$; forming the latter is preferred for soot reduction because one oxygen atom sequesters one carbon atom from forming a soot precursor. The present chemical kinetic modeling study on DEC indicates that molecular elimination, leading to ethylene, $\mathrm{CO}_{2}$, and ethanol, is a predominant consumption pathway. In relation to soot precursor formation, this suggests that two of the fuel bound oxygen atoms usually sequester only one carbon atom, whereas the third oxygen atoms leads to $\mathrm{CO}$ formation via ethanol decomposition. Pepiot et al. [60] report that oxygen molecules in esters are less effective at improving the threshold sooting index (TSI) of oxygenate/heptane/toluene mixtures than oxygen molecules in alcohols and aldehydes. Interestingly, they report that the oxygen molecules in DEC have little effect in reducing the sooting tendency of the fuel mixture studied, and improvements in TSI of mixtures is primarily due to dilution of the aromatic fraction. Our model suggests that this ineffectiveness of the oxygenated moiety can be attributed to the fact that DEC undergoes molecular elimination, which leaves two of the fuel bound oxygen atoms in $\mathrm{CO}_{2}$ and one in ethanol. The formation of $\mathrm{CO}_{2}$ is not beneficial for soot reduction in the TSI experimental configuration.

McEnally and Pfefferle recently presented the yield sooting index (YSI) term to quantify a fuel's sooting propensity relative to $n$-hexane (YSI=0) and benzene (YSI=100) in an atmospheric, non-premixed, methane/air flame [61]. The relatively low yield sooting index of DEC (YSI = -23.4) indicates a reduction in soot precursor formation; however, this can be attributed to the fact that the small carbon chain in DEC leads to the formation of smaller alkenes (e.g., ethylene) when compared to the longer alkyl chain in the reference $n$-hexane fuel additive. The addition of long alkyl chains to the methane-air flame enhances pathways that can form aromatic rings that eventually lead to soot. The propensity of carbonates to form $\mathrm{CO}_{2}$ is also not beneficial in this configuration; however, McEnally and Pfefferle explain that inserting an oxygenate group 
within a carbon chain minimizes sooting propensity. This explains why DEC with its oxygen atoms in the center of its ethyl groups has a lower YSI (-23.4) than ethyl propionate (YSI = -15.6) with its oxygen atoms positioned slightly off-center in its "carbon chain" which is lower than methyl pentanoate (YSI $=-12.6$ ) with its oxygen atoms on the end of the carbon chain.

\section{Conclusions}

Species concentrations were measured for DEC using a the jet-stirred reactor at a pressure of 10 atm, at equivalence ratios of $0.5,1.0$ and 2.0 , and over a temperature range of 500-1200 K. Ignition delay times for DEC were measured in a shock tube and in a RCM at a pressure of 30 atm, at equivalence ratios of $0.5,1.0$ and 2.0 , and over a temperature range of $660-1300 \mathrm{~K}$. Although DEC has no possible 6- and 7-membered ring $\mathrm{RO}_{2} \rightleftharpoons \mathrm{QOOH}$ isomerization reactions, the experimental results for ignition in the RCM showed near NTC behavior. The rate constants of 5-, 8- and 9-membered ring $\mathrm{RO}_{2} \rightleftharpoons \mathrm{QOOH}$ isomerization reactions for DEC were estimated using ab-initio computations and the estimated rate constants were in good agreement with ab-initio derived rate rules of alkane $\mathrm{RO}_{2} \rightleftharpoons \mathrm{QOOH}$ isomerization reactions. A chemical kinetic model for DEC including both high-temperature and low-temperature oxidation mechanisms was developed and the model predictions were compared with the experimental data. The present model captures the overall trends of intermediate species concentrations and ignition delay times as a function of temperature.

\section{Acknowledgements}

This work was performed under the auspices of the US Department of Energy by Lawrence Livermore National Laboratory under Contract DE-AC52-07NA27344. The work at LLNL work was supported by the US Department of Energy, Office of Vehicle Technologies and the Office of Basic Energy Sciences, and the authors thank program managers Gurpreet Singh, 
Kevin Stork, and Wade Sisk. The work performed at CNRS was funded via the ERC Advanced Grant "2G-CSafe: Combustion of Sustainable Alternative Fuels for Engines used in aeronautics and automotives", Grant Agreement Number 291049 (PI Philippe Dagaut). Co-author SMS acknowledges fellowship support from NSERC of Canada and from the KAUST Clean Combustion Research Center. Co-author ADPC acknowledges the Ministry of Agriculture, the Government of César, Colciencias, Popular University of Cesar and the University of Antioquia in Colombia, for the doctoral scholarship received. Co-author HN acknowledges the financial support "Young Researcher Overseas Visits Program for Vitalizing Brain Circulation" from Japan Society for the Promotion of Science.

\section{References}

[1]N.S. Roh, B.C. Dunn, E.M. Eyring, R.J. Pugmire, H.L.C. Meuzelaar, Fuel Process. Tech. 83 (1-3) (2003) 27-38.

[2]B.C. Dunn, C. Guenneau, S.A. Hilton, J. Pahnke, E.M. Eyring, Energy Fuels 16 (1) (2002) $177-181$.

[3]M. Kozak, J. Merkisz, P. Bielaczyc, A. Szczotka, SAE Paper 2009-01-2696, (2009).

[4] M. A. Pacheco, C. L. Marshall, Energy Fuels 11(1) (1997) 2-29.

[5] S. J. Harris, A. Timmons, W. J. Pitz, J. Power Sources 193(2) (2009) 855-858.

[6] Y. Ren, Z. Huang, H. Miao, Y. Di, D. Jiang, K. Zeng, B. Liu, X. Wang, Fuel 87(12) (2008) 2691-2697.

[7] L. Liang, C. V. Naik, K. V. Puduppakkam, C. Wang, A. Modak, E. Meeks, H.-W. Ge, R. D. Reitz, C. J. Rutland, SAE Paper 2010-01-0178, 2010.

[8] Z. Luo, M. Plomer, T. Lu, S. Som, D. E. Longman, Combust. Theor. Model. 16(2) (2012) $369-385$. 
[9] F. Contino, H. Jeanmart, T. Lucchini, G. D'Errico, Proc. Combust. Inst. 33 (2011) $3057-3064$.

[10] G. Dayma, S. M. Sarathy, C. Togbe, C. Yeung, M. J. Thomson, P. Dagaut, Proc. Combust. Inst. 33 (2011) 1037-1043.

[11]P. Dagaut, M. Cathonnet, J. P. Rouan, R. Foulatier, A. Quilgars, J. C. Boettner, F. Gaillard, H. James, J. Phys. E Sci. Instrum. 19(3) (1986) 207-209.

[12]H. Nakamura, D. Darcy, M. Mehl, C.J. Tobin, W.K. Metcalfe, W.J. Pitz, C.K. Westbrook, H.J. Curran, Combust. Flame 161(1) (2014) 49-64.

[13]D. Darcy, H. Nakamura, C.J. Tobin, M. Mehl, W.K. Metcalfe, W.J. Pitz, C.K. Westbrook, H.J. Curran, Combust. Flame 161(1) (2014) 65-74.

[14]C. Morley, Gaseq, Version 0.76, 2004, <http://www.gaseq.co.uk>.

[15]W.S. Affleck, A. Thomas, Proc. Inst. Mech. Eng. 183 (1968), pp. 365-385.

[16] J. Würmel, J.M. Simmie, H.J. Curran, Int. J. Vehicle Des. 44 (2007) 84-106.

[17] S.M. Gallagher, H.J. Curran, W.K. Metcalfe, D. Healy, J.M. Simmie, G. Bourque, Combust. Flame, 153(1-2) (2008) 316-333.

[18]D. Healy, N.S. Donato, C.J. Aul, E.L. Petersen, C.M. Zinner, G. Bourque, H.J. Curran, Combust. Flame, 157(8) (2010) 1526-1539.

[19]P.A. Glaude, W.J. Pitz, M.J. Thomson, Proc. Combust. Inst. 30 (2005) 1111-1118.

[20]W.K. Metcalfe, S.M. Burke, S.S. Ahmed, H.J. Curran, Int. J. Chem. Kinet. 45 (2013) $638-675$.

[21] J. Herzler, J. A. Manion, W. Tsang, J. Phys. Chem. A 101(30) (1997) 5494-5499.

[22]H. Bennadji, P.A. Glaude, L. Coniglio, F. Billaud, Fuel 90(11) (2011) 3237-3253.

[23]W.K. Metcalfe, C. Togbé, P. Dagaut, H.J. Curran, J.M. Simmie, Combust. Flame 156(1) (2009) 250-260.

[24]R. Notario, J. Quijano, C. Sánchez, E. Vélez, J. Phys. Org. Chem. 18(2) (2005) 134-141. 
[25] J. Mendes, C.-W. Zhou, H.J. Curran, J. Phys. Chem. A 118(27) (2014) 4889-4899.

[26] J. Mendes, C.-W. Zhou, H.J. Curran, J. Phys. Chem. A 117(51) (2013) 14006-14018.

[27] S.M. Sarathy, C.K. Westbrook, M. Mehl, W.J. Pitz, C. Togbe, P. Dagaut, H. Wang, M.A. Oehlschlaeger, U. Niemann, K. Seshadri, P.S. Veloo, C. Ji, F.N. Egolfopoulos, T. Lu, Combust. Flame 158(12) (2011) 2338-2357.

[28]C-W. Zhou, J.M. Simmie, H.J. Curran, Phys. Chem. Chem. Phys. 12(26) (2010) $7221-7233$.

[29]C-W. Zhou, J.M. Simmie, H.J. Curran, Combust. Flame 158(4) (2011) 726-731.

[30]K. Yasunaga, F. Gillespie, J.M. Simmie, H.J. Curran, Y. Kuraguchi, H. Hoshikawa, M. Yamane, Y. Hidaka, J. Phys. Chem. A 114 (2010) 9098-9109.

[31]L.K. Huynh, A. Violi, J. Org. Chem. 73(1) (2008) 94-101.

[32] Private communication with S.J. Klippenstein, (2013).

[33]W.J. Pitz, C.K. Westbrook, Combust. Flame 63(1-2) (1986) 113-133.

[34]A. Farooq, D.F. Davidson, R.K. Hanson, L.K. Huynh, A. Violi, Proc. Combust. Inst. 32 (1) (2009) 247-253.

[35]G. Mittal, S.M. Burke, V.A. Davies, B. Parajuli, W.K. Metcalfe, H.J. Curran, Combust. Flame 161(5) (2014) 1164-1171.

[36]R. Sivaramakrishnan, M.C. Su, J.V. Michael; S.J. Klippenstein, L.B. Harding, B.J. Ruscic, J. Phys. Chem. A 114 (2010) 9425-9439.

[37]I. Stranic, G.A. Pang, R.K. Hanson, D.M. Golden, C.T. Bowman, J. Phys. Chem. A 118 (2014) 822-828.

[38]C-W. Zhou, J.M. Simmie, H.J. Curran, Int. J. Chem. Kinet. 44(3) (2012) 155-164.

[39] Gaussian 09, Revision C.01, M.J. Frisch, G.W. Trucks, H.B. Schlegel, G.E. Scuseria, M.A. Robb, J.R. Cheeseman, G. Scalmani, V. Barone, B. Mennucci, G.A. Petersson, H. Nakatsuji, M. Caricato, X. Li, H.P. Hratchian, A.F. Izmaylov, J. Bloino, G. Zheng, J.L. Sonnenberg, M. 
Hada, M. Ehara, K. Toyota, R. Fukuda, J. Hasegawa, M. Ishida, T. Nakajima, Y. Honda, O. Kitao, H. Nakai, T. Vreven, J.A. Montgomery, Jr., J.E. Peralta, F. Ogliaro, M. Bearpark, J.J. Heyd, E. Brothers, K.N. Kudin, V.N. Staroverov, R. Kobayashi, J. Normand, K. Raghavachari, A. Rendell, J.C. Burant, S.S. Iyengar, J. Tomasi, M. Cossi, N. Rega, J.M. Millam, M. Klene, J.E. Knox, J.B. Cross, V. Bakken, C. Adamo, J. Jaramillo, R. Gomperts, R.E. Stratmann, O. Yazyev, A.J. Austin, R. Cammi, C. Pomelli, J.W. Ochterski, R.L. Martin, K. Morokuma, V.G. Zakrzewski, G.A. Voth, P. Salvador, J.J. Dannenberg, S. Dapprich, A.D. Daniels, Ö. Farkas, J.B. Foresman, J.V. Ortiz, J. Cioslowski, and D.J. Fox, Gaussian, Inc., Wallingford CT, 2010.

[40] MultiWell-2011.3 Software, Aug 2011, designed and maintained by J.R. Barker with contributors N.F. Ortiz, J.M. Preses, L.L. Lohr, A. Maranzana, P.J. Stimac, T. L. Nguyen, and T. J. Dhilip Kumar, University of Michigan, Ann Arbor, MI; http://aoss.engin.umich.edu/multiwell/

[41]J.R. Barker, Int. J. Chem. Kinetics 33 (2001) 232-45.

[42] S.M. Villano, L.K. Huynh, H.H. Carstensen, A.M. Dean, J. Phys. A 115(46) (2011) $13425-13442$.

[43]M. Saeys, M.F. Reyniers, G.B. Marin, V. Van Speybroeck, M. Waroquier, J. Phys. Chem. A 107(43) (2003) 9147-9159.

[44]H.-H. Carstensen, A.M. Dean, O. Deutschmann, Proc. Combust. Inst. 31 (2007) 149-157.

[45]R. Asatryan, J.W. Bozzelli, J. Phys. Chem. A 114(29) (2010) 7693-7708.

[46]C.D. Wijaya, R. Sumathi, W.H. Green, J. Phys. Chem. A 107(24) (2003) 4908-4920.

[47]E.R. Ritter, J.W. Bozzelli, Int. J. Chem. Kinet. 23(9) (1991) 767-778.

[48] S.W. Benson, Thermochemical Kinetics, John Wiley, New York, (1976) 272-298.

[49]Private communication from J.W. Bozzelli, (2001).

[50]L.S. Tee, S. Gotoh, W.E. Stewart, Ind. Eng. Chem. Fund. 5(3) (1966) 356-363. 
[51]C.L. Yaws, Yaws' Thermophysical Properties of Chemicals and Hydrocarbons (Electronic Edition).

[52]LLNL mechanism toolkit, M.J. McNenly, personal communication, (2014).

[53]CHEMKIN-PRO Release 15113, 28-Nov-2012, Reaction Design, Inc: San Diego, CA, 2012.[54] M.M. Kopp, N.S. Donato, E.L. Petersen, W.K. Metcalfe, S.M. Burke, H.J. Curran, J. Propul. Power 30(3) (2014) 790-798.

[55]M.M. Kopp, E.L. Petersen, W.K. Metcalfe, S.M. Burke, H.J. Curran, J. Propul. Power 30(3) (2014) 799-811.

[56]D.B. Lenhert, D.L. Miller, N.P. Cernansky, Combust. Sci. Technol. 179(5) (2007) 845-861.

[57]A. Farooq, D.F. Davidson, R.K. Hanson, L.K. Huynh, A. Violi, Proc. Combust. Inst. 32 (2009) 247-253.

[58]L.R. McCunn, K.C. Lau, M.J. Krisch, L.J. Butler, J.W. Tsung, J.J. Lin, J. Phys. Chem. A 110(4) (2006) 1625-1634.

[59]C.K. Westbrook, W.J. Pitz, H.J. Curran, J. Phys. Chem. A 110(21) (2006) 6912-6922.

[60]P. Pepiot-Desjardins, H. Pitsch, R. Malhotra, S.R. Kirby, A.L. Boehman, Combust. Flame 154(1-2) (2008) 191-205.

[61]C.S. McEnally, L.D. Pfefferle, Environ. Sci. Technol. 45(6) (2011) 2498-2503. 
Table 1: Rate constant expressions of key DEC reactions $\left(\mathrm{k}=\mathrm{AT}^{\mathrm{n}} \exp \left(-\mathrm{E}_{\mathrm{a}} / \mathrm{RT}\right)\right.$, units: kcal-mole-sec)

\begin{tabular}{|c|c|c|c|c|c|}
\hline No. & Reaction & A & $\mathrm{n}$ & $\mathrm{E}_{\mathrm{a}}$ & Reference \\
\hline 1 & $\mathrm{CCOC}^{*} \mathrm{OOCC} \Leftrightarrow=\mathrm{C}_{2} \mathrm{H}_{4}+\mathrm{CCOC}^{*} \mathrm{OOH}$ & $1.1 \mathrm{E} 13$ & 0 & 46.3 & [21] \\
\hline 2 & $\mathrm{CCOC} * \mathrm{OOH}=>\mathrm{C}_{2} \mathrm{H}_{5} \mathrm{OH}+\mathrm{CO}_{2}$ & $1.24 \mathrm{E} 13$ & 0 & 32.7 & [24] \\
\hline 3 & $\mathrm{CCOC} * \mathrm{OOJ}+\mathrm{C}_{2} \mathrm{H}_{4} \Leftrightarrow \mathrm{CJCOC} * \mathrm{OOCC}$ & $2.28 \mathrm{e}+11$ & 0.667 & 23.5 & See text, \\
\hline 4 & $\mathrm{CCOCJ} * \mathrm{O}+\mathrm{CH}_{3} \mathrm{CHO} \Leftrightarrow=\mathrm{CCJOC} * \mathrm{OOCC}$ & 11.1 & 3.14 & 11.2 & {$[31]$} \\
\hline 5 & $\mathrm{CCOCJ} * \mathrm{O}<=>\mathrm{C}_{2} \mathrm{H}_{5} \mathrm{O}+\mathrm{CO}$ & $9.02 \mathrm{E} 14$ & -1.72 & 21.77 & [32], a \\
\hline 6 & $\mathrm{CCOCJ} * \mathrm{O}<=>\mathrm{C}_{2} \mathrm{H}_{5}+\mathrm{CO}_{2}$ & $1.04 \mathrm{E} 18$ & -2.10 & 12.83 & [32], a \\
\hline 7 & CCOC $*$ OOCCOO $-1<=>$ CCOC $*$ OOCCJOOH -1 & $5.86 \mathrm{E} 11$ & 0 & 33.76 & this study \\
\hline 8 & $\mathrm{CCOC} * \mathrm{OOCCOO}-1<=>\mathrm{CCJOC} * \mathrm{OOCCOOH}-1$ & $2.59 \mathrm{E} 09$ & 0 & 17.91 & this study \\
\hline 9 & $\mathrm{CCOC} * \mathrm{OOCCOO}-1<=>\mathrm{CJCOC} * \mathrm{OOCCOOH}-1$ & $9.18 \mathrm{E} 08$ & 0 & 19.16 & this study \\
\hline 10 & $\mathrm{CCOC} * \mathrm{OOCCOO}-2<=>\mathrm{CCOC} * \mathrm{OOCJCOOH}-2$ & $2.95 \mathrm{E} 12$ & 0 & 28.62 & this study \\
\hline 11 & $\mathrm{CCOC} * \mathrm{OOCCOO}-2<=>\mathrm{CCJOC} * \mathrm{OOCCOOH}-2$ & $2.31 \mathrm{E} 11$ & 0 & 21.37 & this study \\
\hline
\end{tabular}

Notation: "*" indicates double bond. "J" indicates radical site on the preceeding carbon atom. "-1" indicates $\alpha$ site and " 2 " indicates the $\beta$ site. See species glossary in supplemental for details. a: data at 10 atm are shown here. See supplementary file for details of PLOG parameters. 


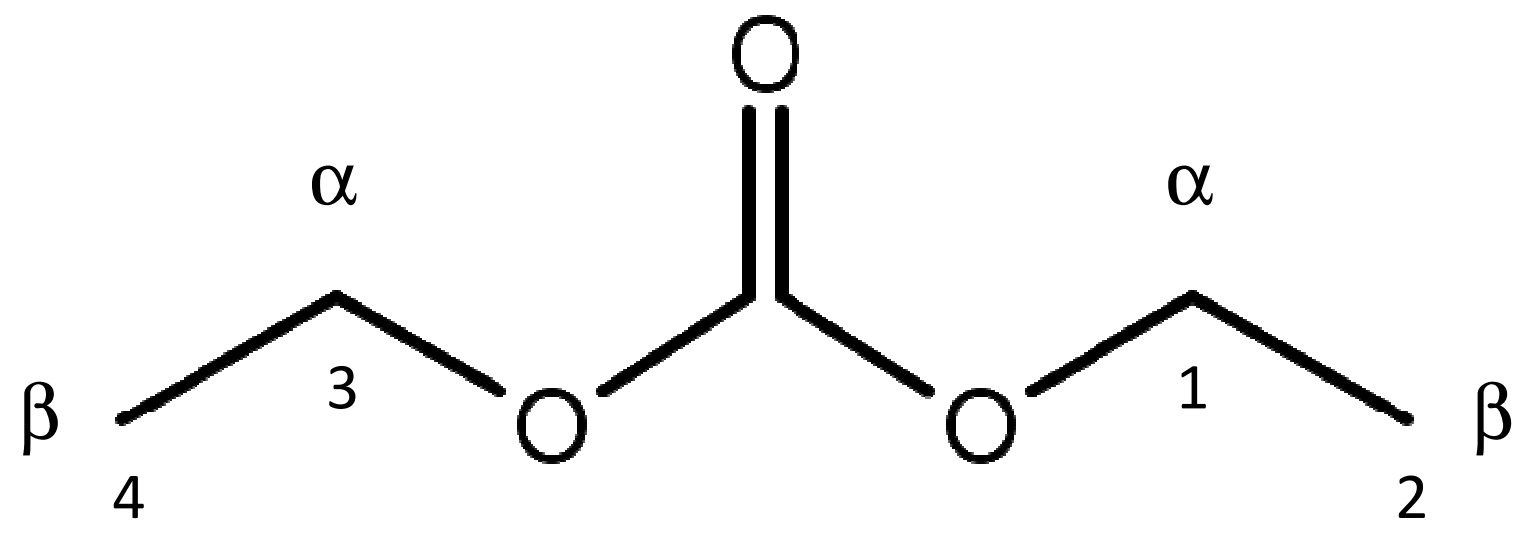

Fig. 1 Diethylcarbonate molecule with labels of the H-atom abstraction sites. 


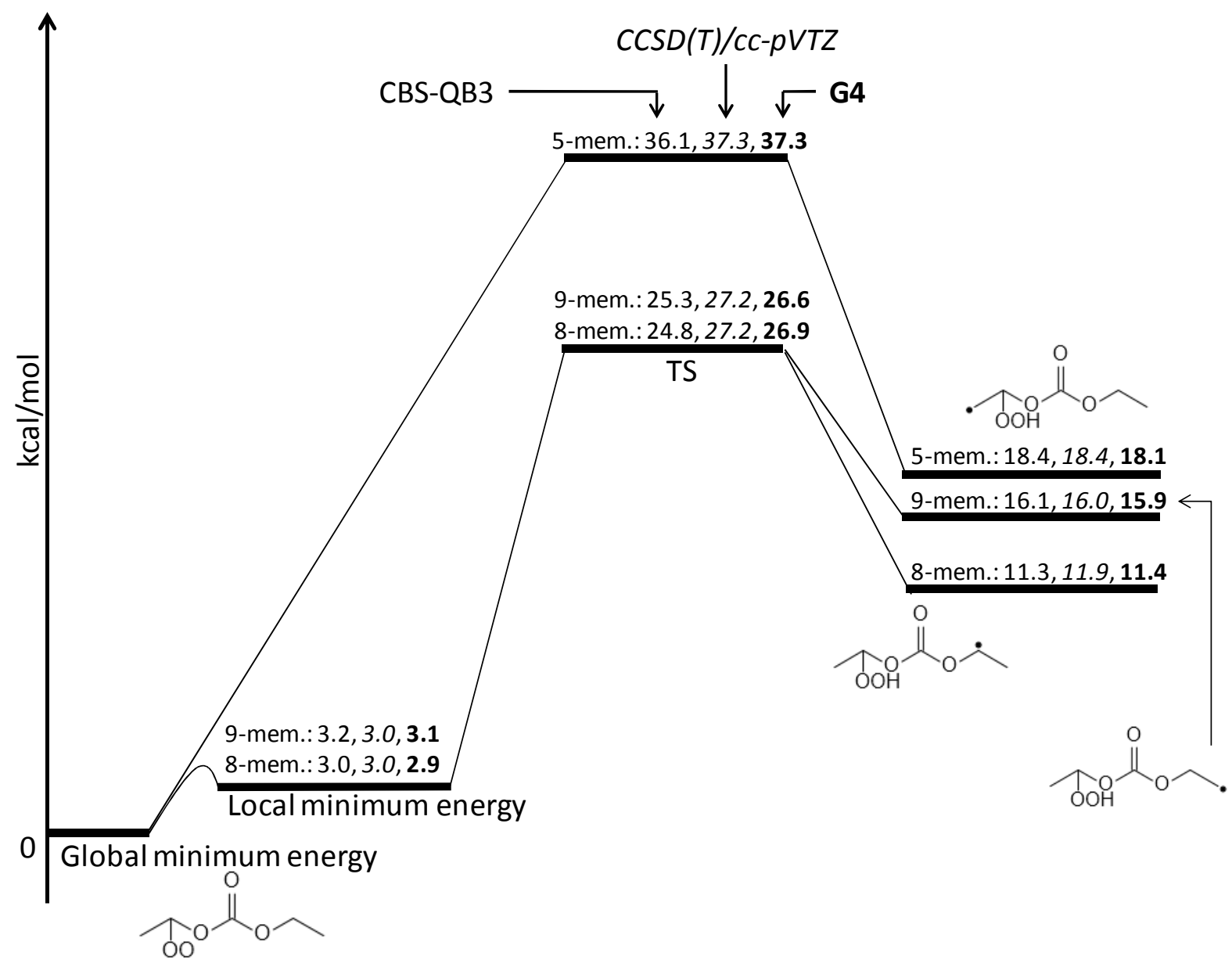

Fig. 2 Potential energy surface of $\mathrm{RO}_{2} \rightleftharpoons \mathrm{QOOH}$ isomerization reactions. 


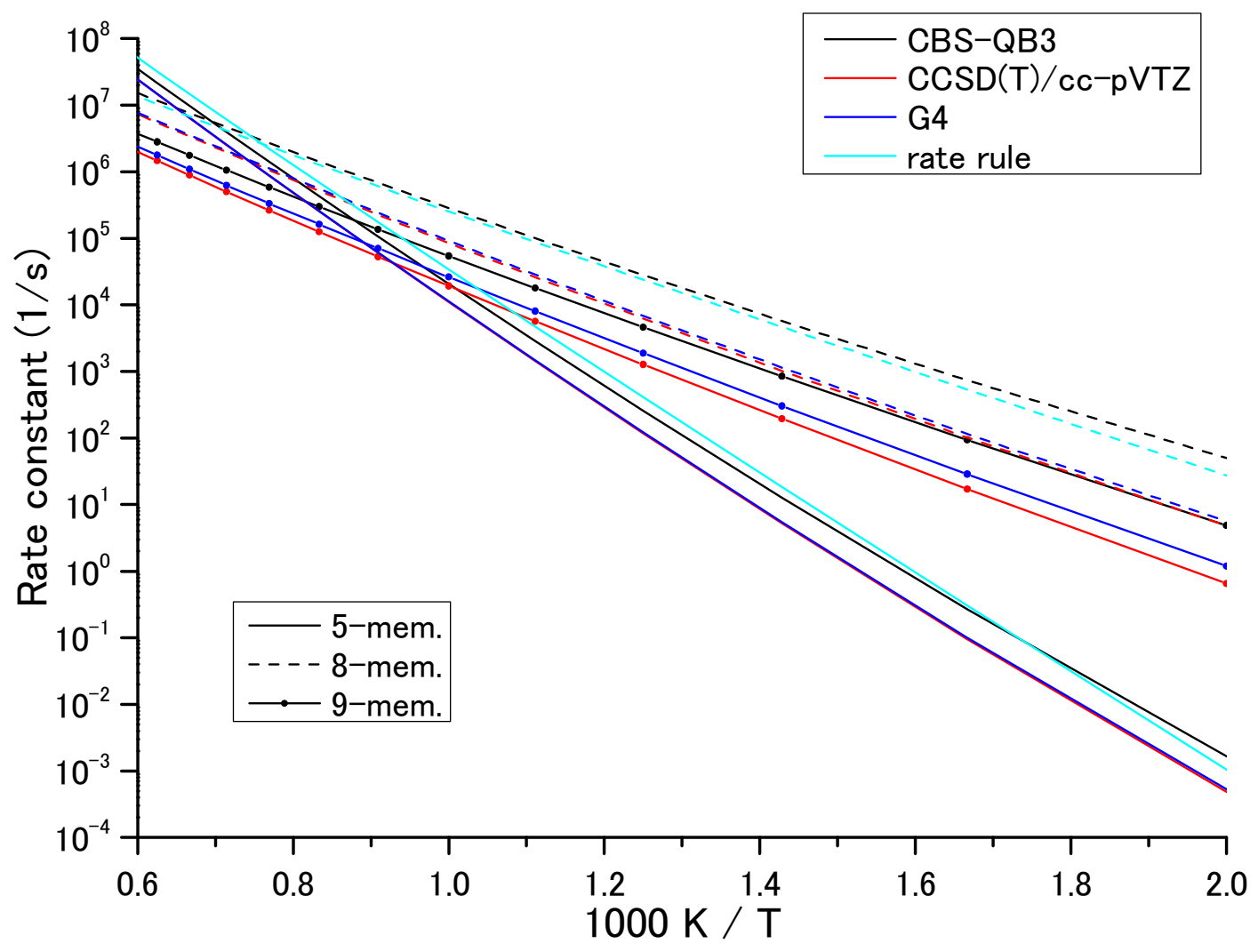

Fig. 3 Computed rate constants of $\mathrm{RO}_{2} \rightleftharpoons \mathrm{QOOH}$ isomerization reactions (line style indicates ring structure; line color indicates method; rate rule of alkane $\mathrm{RO}_{2} \rightleftharpoons \mathrm{QOOH}$ isomerization reactions: [42] There is no "rate rule" available for the 9-membered ring.). 

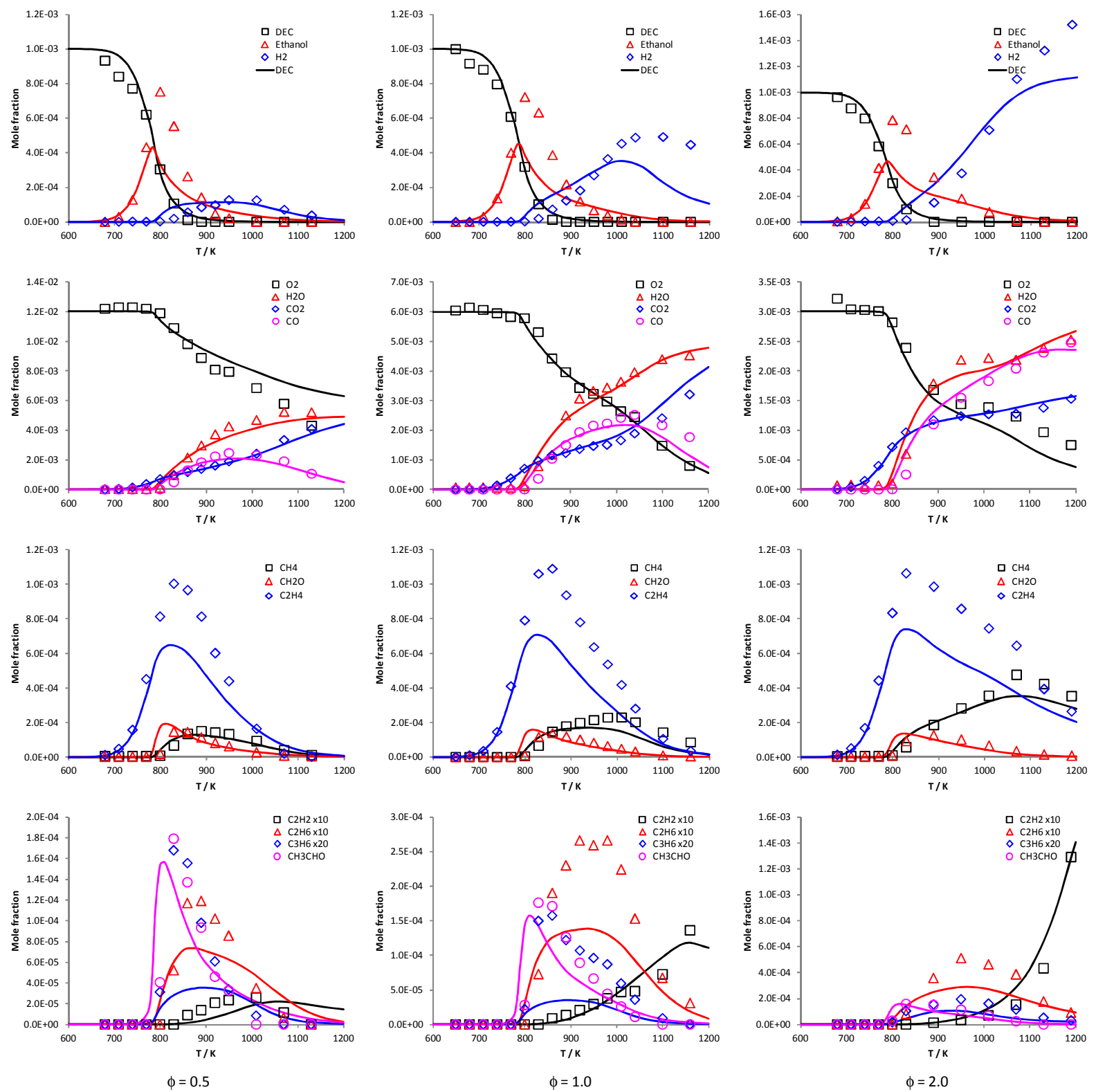

Fig. 4 Experimental (symbols) and modeling (lines) results for DEC in a jet stirred reactor at $10 \mathrm{~atm}$ with a $0.7 \mathrm{~s}$ residence time, $1000 \mathrm{ppm}$ of fuel, and for three different equivalence ratios $(0.5,1.0$ and 2.0). 


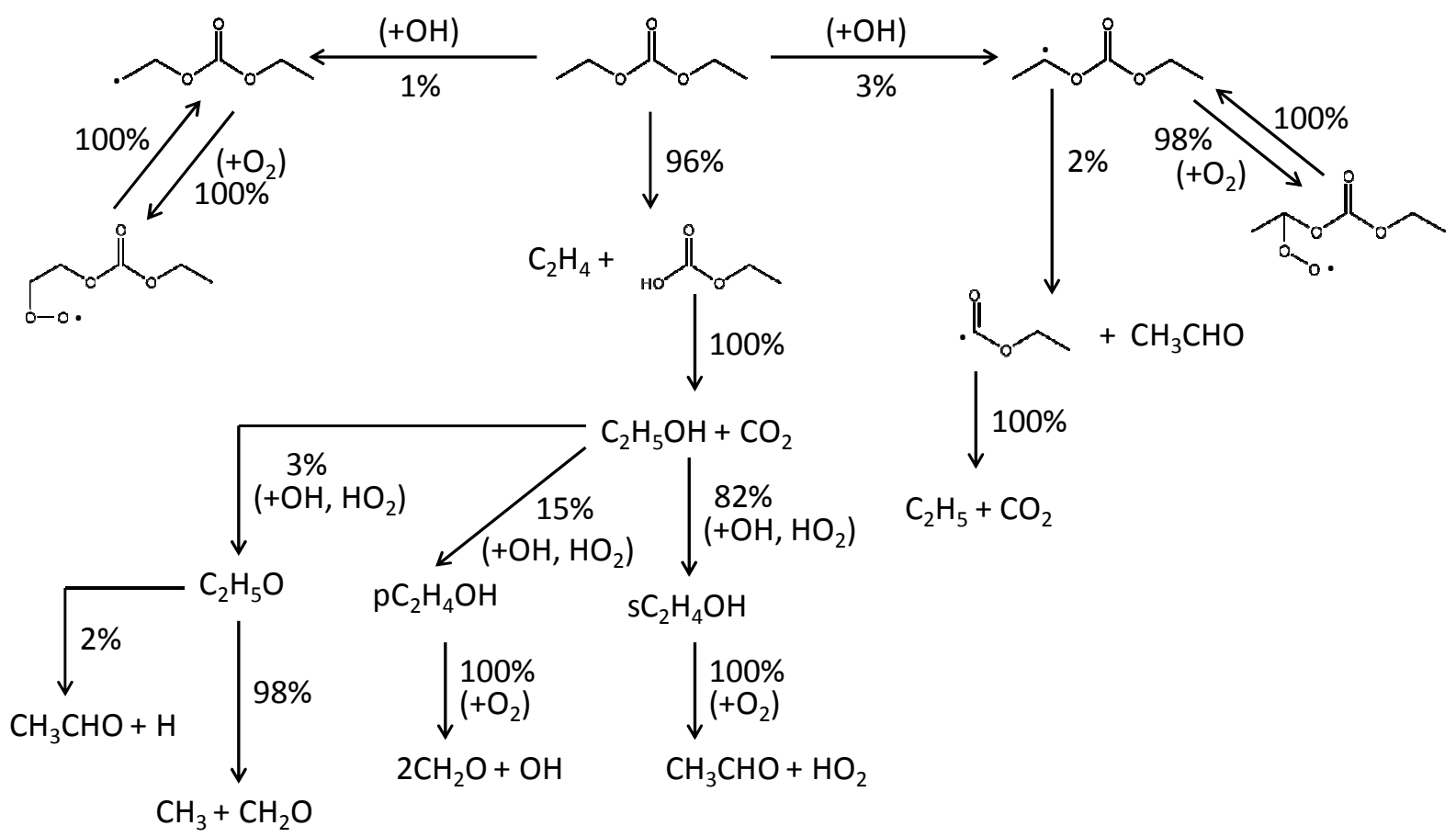

Fig. 5 Reaction pathways for DEC oxidation at $50 \%$ fuel consumed in a JSR at $10 \mathrm{~atm}, \tau=0.7 \mathrm{~s}, \varphi=$ $1.0, T=780 \mathrm{~K}$ and initial fuel mole fraction of $0.1 \%$. Percentages represent the net flux of reaction from the indicated species. 


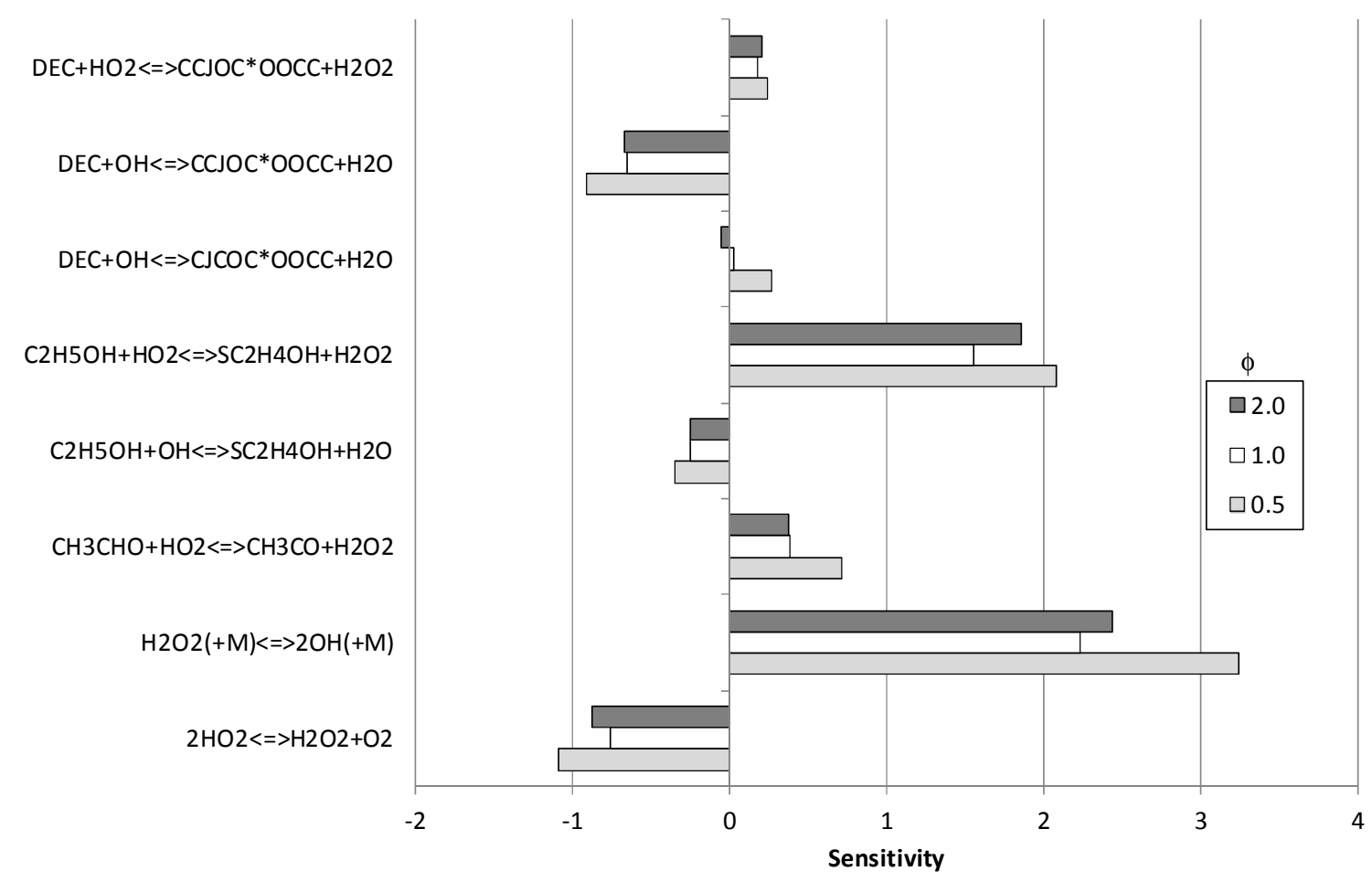

Fig. 6 Sensitivity of ÖH concentration to reaction rate A-factors in the JSR at 780K, 10 atm, and $\varphi$ $=0.5,1.0$ and 2.0. 


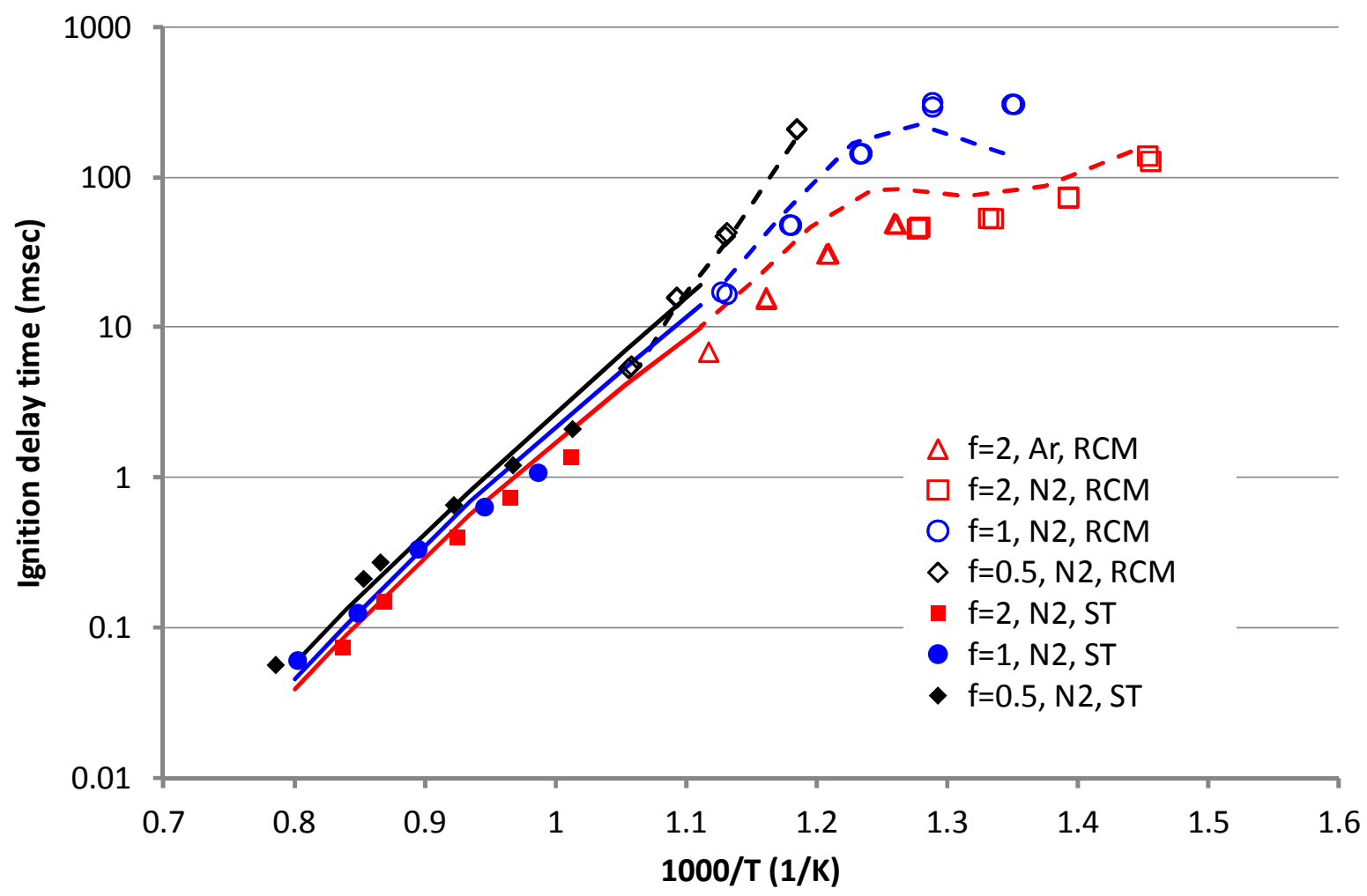

Fig. 7 Ignition delay times for DEC/'air' mixtures at $30 \mathrm{~atm}$ and three different equivalence ratios $(0.5,1.0$ and 2.0) in a shock tube and a rapid compression machine; solid symbols: shock tube; open symbols: RCM; solid line: adiabatic simulation; dashed lines: RCM simulation including facility effects. 


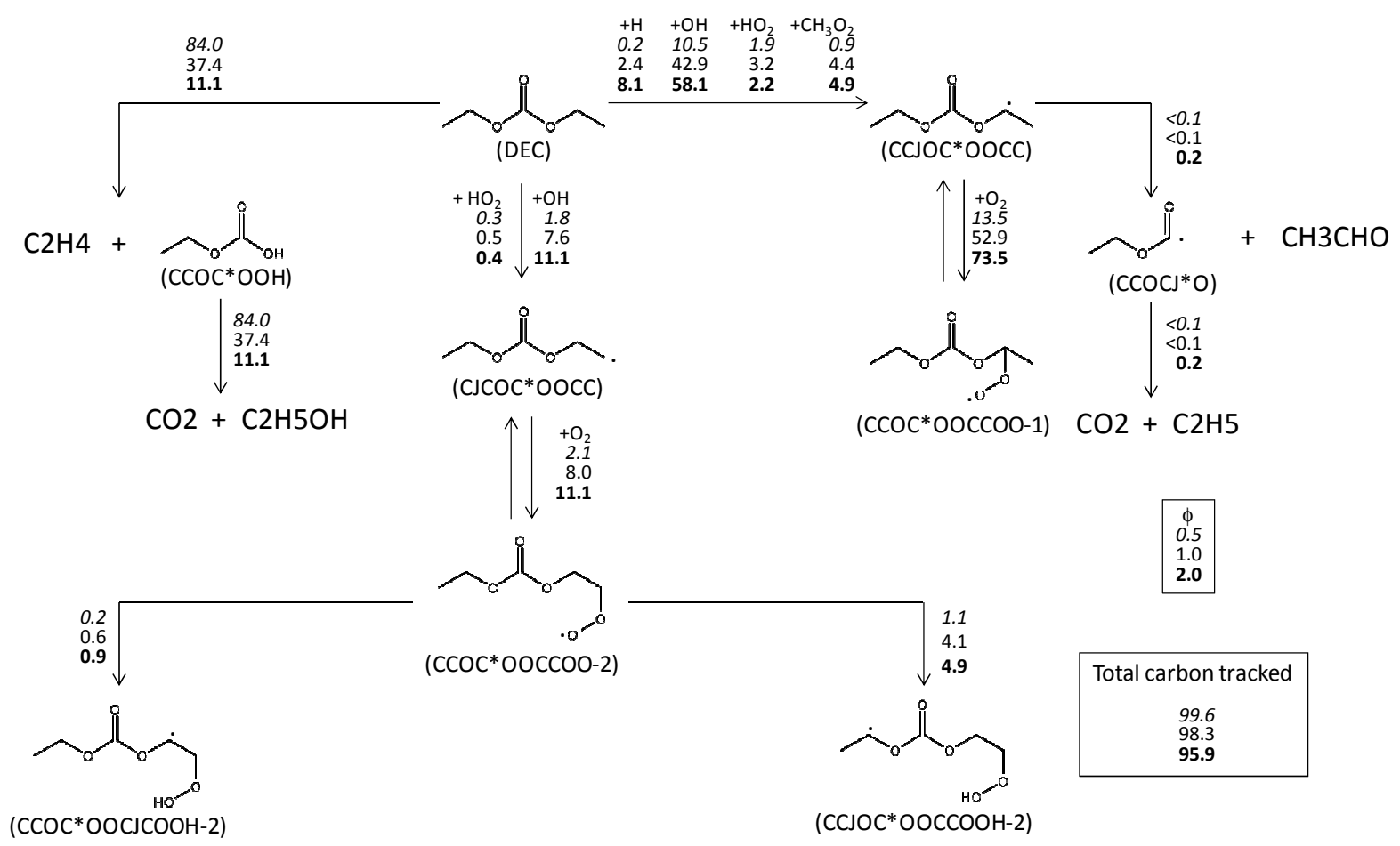

Fig. 8 Reaction pathways for DEC ignition at $800 \mathrm{~K}, 30 \mathrm{~atm}$ and $15 \%$ fuel conversion. Numbers are percent contribution to the consumption of the species on the source side of the arrow. Italic, normal and bold fonts of numbers indicate $\phi=0.5,1.0$ and 2.0 , respectively. 


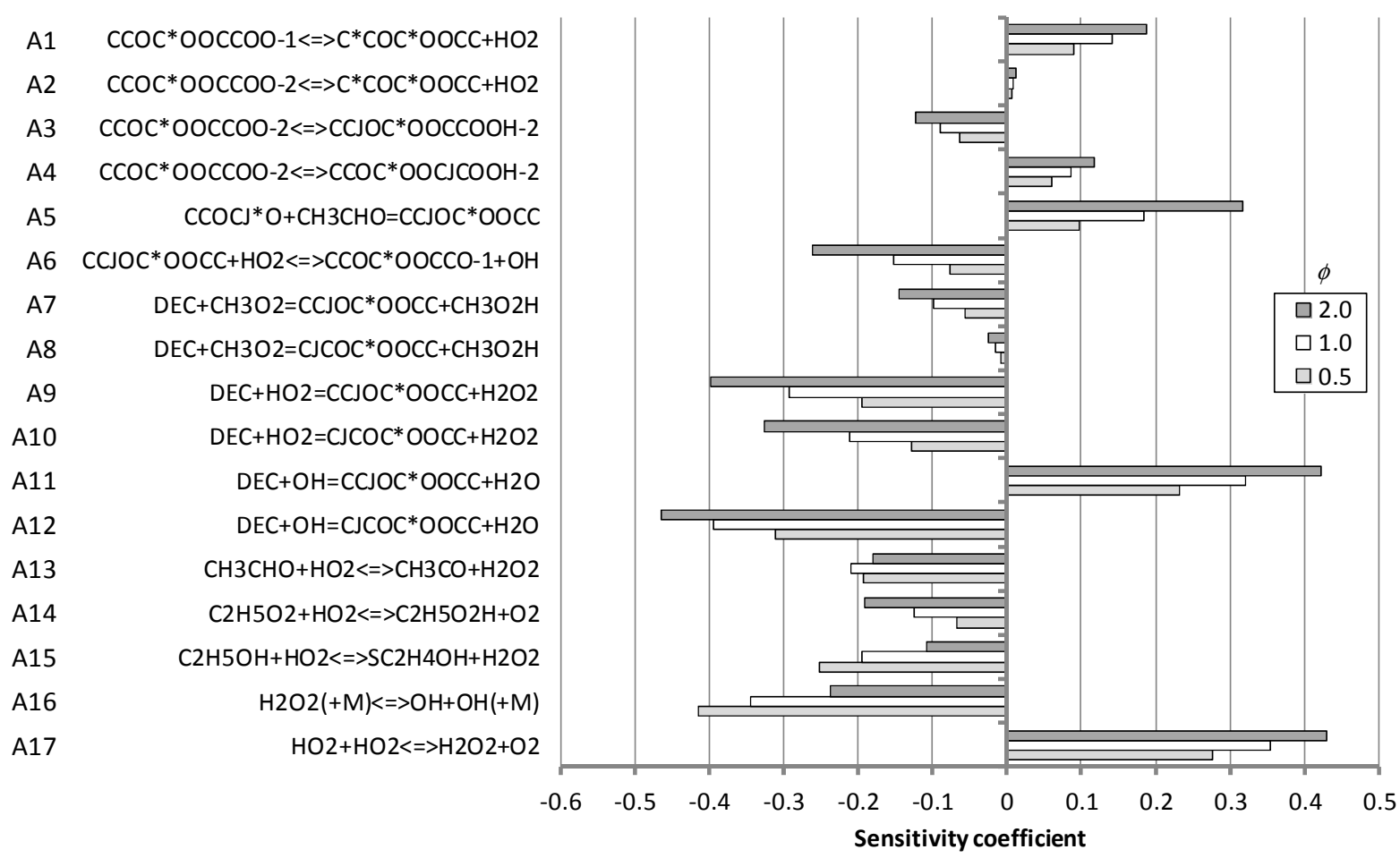

Fig. 9 Sensitivity coefficients on ignition delay time of DEC/air mixtures at $800 \mathrm{~K}$ and 30 atm. 